\title{
Interaction of Squeeze Film Dampers and Hole Feed Systems and Its Influence on the Dynamics of a Jeffcott Rotor
}

\author{
Fabiano A. Rodrigues, Fabrice Thouverez, and Louis Jezequel \\ Ecole Centrale de Lyon —Laboratoire de Tribologie et Dynamique des Systèmes, \\ Ecully, France
}

The oil feeding of a squeeze film damper through holes can be an interesting solution to improve the damper's energy dissipation capability since it increases the journal's effective squeezing surface. While groove feeding has been extensively studied, only a few works have addressed the problem of hole fed dampers. The squeeze film damper model may be able to estimate the pressure at the feed holes as well as the flow into the film. A fundamental issue in the modeling of the hole feed system is the choice of the adequate boundary conditions. Existing published models consider the supply pressure to be constant at a specific section of the hydraulic system. The pressures at the oil injection holes are then obtained via local flow balances taking into account a linear flow resistance across the feed conduits. The model developed in the present work is based on the application of the simplified form of the energy equation commonly used in hydraulics, with approximate pressure drop coefficients. As a boundary condition we impose the power supplied to the pump. The nonlinear hydraulics problem is coupled with the squeeze flow and the Newton-Raphson method is employed to solve the set of nonlinear equations. The influence of the hole feed system on the unbalance response and stability of a Jeffcott rotor is analyzed in regards to the number of feed holes and the power supplied to the pump. The feed system behavior is also studied.

Keywords Hole feeding, Jeffcott rotor, Nonlinear dynamics, Squeeze film damper, Stability

Thanks to their damping potential, squeeze film dampers (SFD) are considered to be one of the most important

Received 30 March 2003; accepted 12 June 2003.

Address correspondence to Fabiano A. Rodrigues, Ecole Centrale de Lyon-LTDS, 36, Avenue Guy de Collongue, Ecully 69130, France. E-mail: fabiano@mecasola.ec-lyon.fr technological developments to occur in rotating machinery during the last three decades. When correctly conceived, these dampers can improve rotor stability, attenuate vibration levels, and reduce transmissibility.

A significant number of theoretical and experimental works have been published since the 1960s as the interest in the application of this kind of damper grew strong. As far as the oil film pressure distribution is concerned, the majority of the studies have focused on cavitation modeling, fluid inertia effects, non-Newtonian fluid behavior, and operation with bubbly oil. Despite the consensus about the importance of the damper's boundary conditions, namely the feed system and the leakage conditions, a relatively limited number of works addressed these issues. Regarding the feed system, circumferential groove-fed dampers have already been extensively examined by San Andres (1992) and Arauz and San Andres (1994), who evidenced the influence of the interaction between land and groove flows on the SFD performance. However, for hole fed dampers, a configuration which can turn out to be an interesting way to improve damping capability (Wang and Hahn, 1995), only a few models have been proposed.

The hole feed system affects the damper performance in a direct way, in view of the pressure build up resulting from the interaction between the film land flow and the injection holes. An indirect influence can also show up whenever the feeding capability is not high enough to prevent air entrainment into the film, which leads to operation with a bubbly oil (Diaz and San Andres, 2001). Hence, the hole feed system model must be able to provide good estimates of the pressure at the oil injection holes as well as of the flow into the film. Marmol and Vance (1978) proposed a finite difference discretization of the Reynolds equation with mesh grid dimensions larger than the feed holes diameter. Equations for the film pressures at the feed holes were obtained via flow balances with a linear flow resistance across the feed conduits. Lund et al. (1983) employed a similar approach but modeled the feed holes as punctual sources. Chen and Hahn (1994) developed a semi analytical model allowing for expeditious SFD forces calculation and examined the error introduced by defining 
the feed holes as mesh points. Even though their models enable a nonlinear flow resistance across the feed conduits to be taken into account, only results for linear flow resistances are presented. All the models cited above suppose that the supply pressure remains constant at a specific section of the feed system. This simplified boundary condition is not always realistic since the reverse flow through the holes caused by the SFD pumplike action is accompanied by pressure fluctuations in the feed system.

In the present work, the feed system is modeled by applying the energy approach commonly used in hydraulics. The net power supplied to the pump is imposed as the problem's boundary condition. Flow balancing at the feed holes position allows for coupling the nonlinear equations describing pressures and flows in the feed system with the linear equations governing the SFD pressure distribution. The resulting set of nonlinear equations are solved by the Newton-Raphson method. Simulations of the dynamics of a Jeffcott rotor are carried out to study the interaction between the feed system and the squeeze flow. The unbalance response and stability of the rotor, as well as the hydraulic system behavior, are analyzed in regards to the number of feed holes and the power supplied to the pump.

\section{SFD PRESSURE DISTRIBUTION MODEL}

The SFD pressure distribution is governed by the classical Reynolds equation with constant fluid properties (Gohar, 1998). This equation, which is commonly accepted as valid except at the oil injection holes, is discretized by central finite differences. A constant leakage coefficient, $\mathrm{Cl}$, is used to simulate the presence of end seals. The boundary conditions at the damper extremities are thus expressed by:

$$
q_{z}\left(\theta, z_{\text {extremities }}\right)=C l\left[P\left(\theta, z_{\text {extremities }}\right)-P_{0}\right]
$$

Following Marmol and Vance (1978), the finite difference grid is defined so that the mesh dimensions are larger than the feed holes diameter. According to Figure 1, flow balancing at the feed holes yields:

$$
\begin{aligned}
- & \frac{h^{3} R \Delta \theta}{12 \mu}\left(\frac{P_{i, j}-P_{i+1, j}}{\Delta z}+\frac{P_{i, j}-P_{i-1, j}}{\Delta z}\right) \\
- & \frac{h^{3} \Delta z}{12 \mu}\left(\frac{P_{i, j}-P_{i, j+1}}{R \Delta \theta}+\frac{P_{i, j}-P_{i, j-1}}{R \Delta \theta}\right)+Q_{\text {hole }}=0
\end{aligned}
$$

Equation (2) links the pressure gradient at the feed holes to the flow across the feed conduits, thus coupling the SFD pressure distribution to the feed system model. The resulting algebraic equations describing the SFD pressure field can be partitioned as follows:

$$
\left[\begin{array}{ll}
K_{11} & K_{12} \\
K_{21} & K_{22}
\end{array}\right]\left\{\begin{array}{l}
P_{\text {land }} \\
P_{\text {hole }}
\end{array}\right\}=\left\{\begin{array}{c}
F_{\text {land }} \\
-Q_{\text {hole }}
\end{array}\right\}
$$

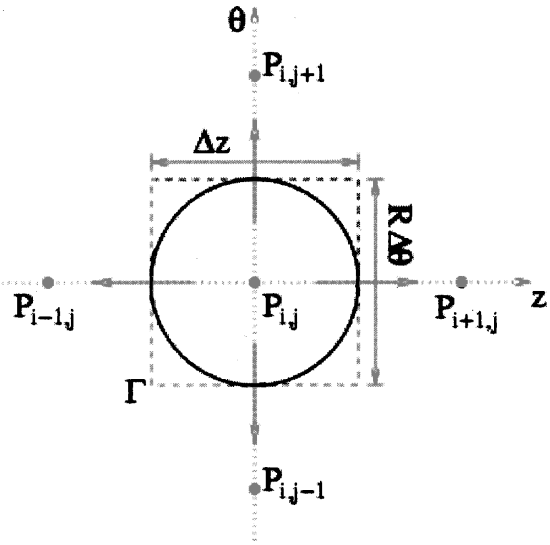

FIGURE 1

Flow balance at the feed holes.

The system of equations above is then condensed on the pressures at the feed holes:

$$
\begin{aligned}
& \left(\left[K_{22}\right]-\left[K_{21}\right]\left[K_{11}\right]^{-1}\left[K_{12}\right]\right)\left\{P_{\text {hole }}\right\} \\
& \quad=\left\{-Q_{\text {hole }}\right\}-\left[K_{21}\right]\left[K_{11}\right]^{-1}\left\{F_{\text {land }}\right\}
\end{aligned}
$$

Once the pressures at the feed holes have been determined, the SFD pressure distribution is calculated from

$$
\left\{P_{\text {land }}\right\}=\left[K_{11}\right]^{-1}\left(\left\{F_{\text {land }}\right\}-\left[K_{12}\right]\left\{P_{\text {hole }}\right\}\right)
$$

and cavitation is treated by setting all pressures inferior to this limit to cavitation pressure.

\section{FEED SYSTEM MODEL}

The feed system is modeled by using classical hydraulics principles (Idel'Cik, 1969). Even though the feed system geometry may vary appreciably, these principles can be employed in any configuration, provided that the singular pressure drop formulae are known. The feed system configuration studied in the present work is shown in Figure 2 and is made up of a pump which draws up oil from an unpressurized reservoir and pumps it into a hydraulic ring by which the fluid is distributed to the feed conduits.

If the SFD is fed by $n$ holes, the $4 n+4$ unknowns of the problem are the pressures $P_{i}$ and flows $Q_{i}, i=1,2,3, \ldots, n, \mathrm{~A}$, $\mathrm{B}, \mathrm{C}, \ldots, \mathrm{N}, \mathrm{N}+1, \mathrm{p}$. In order to avoid matrix ill conditioning during the resolution of the nonlinear problem, the continuity equations at the feed system intersections are written as functions of the Reynolds number, $\operatorname{Re}_{i}=\rho Q_{i} D_{h i} / \mu A_{i}$, in lieu of the flows, and then adimensionalized. For an incompressible fluid, one obtains:

$$
\begin{aligned}
& \operatorname{Re}_{p} \frac{A_{p}}{D_{h p}} \frac{D_{h r}}{A_{r}}+\operatorname{Re}_{N+1}-\operatorname{Re}_{A}=0 \\
& \operatorname{Re}_{A}-\operatorname{Re}_{1} \frac{A_{c}}{D_{h c}} \frac{D_{h r}}{A_{r}}-\operatorname{Re}_{B}=0
\end{aligned}
$$




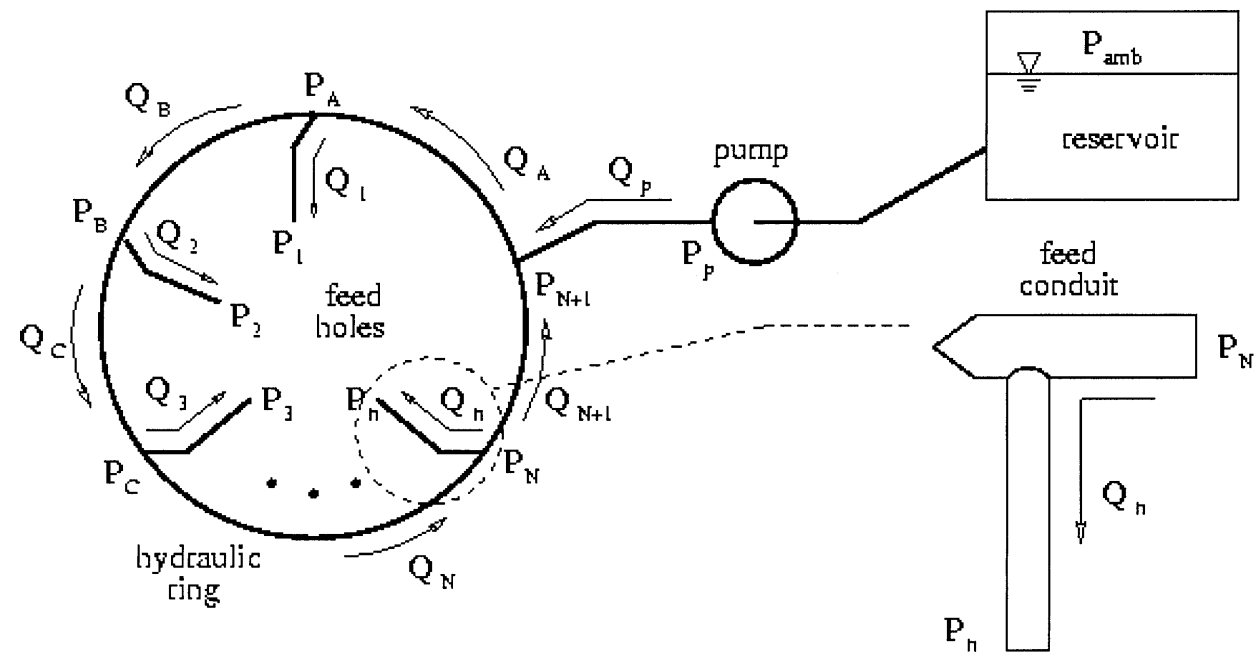

FIGURE 2

Feed system configuration.

$$
\begin{array}{r}
\operatorname{Re}_{B}-\operatorname{Re}_{2} \frac{A_{c}}{D_{h c}} \frac{D_{h r}}{A_{r}}-\operatorname{Re}_{C}=0 \\
\vdots \\
\operatorname{Re}_{N}-\operatorname{Re}_{n} \frac{A_{c}}{D_{h c}} \frac{D_{h r}}{A_{r}}-\operatorname{Re}_{N+1}=0
\end{array}
$$

where,

$A_{p}$ pump exit cross-sectional area

$D_{h p}$ pump exit hydraulic diameter

$A_{r}$ hydraulic ring cross-sectional area

$D_{h r}$ hydraulic ring hydraulic diameter

$A_{c}$ cross-sectional area of the feed conduit part connected to the hydraulic ring

$D_{h c}$ hydraulic diameter of the feed conduit part connected to the hydraulic ring

Supposing that the flow is laminar and that the feed conduit cross-section is circular, the use of the simplified form of the first law of thermodynamics (Idel'Cik, 1969) yields in non dimensional form:

$$
\begin{aligned}
& \left(P_{A}-P_{1}\right) \frac{\rho D_{h r}^{2}}{\mu^{2}} \frac{\operatorname{Re}_{1}}{\left|\operatorname{Re}_{1}\right|}+\left(\frac{D_{h r}^{2}}{D_{h c}^{2}}-\frac{D_{h c}^{2}}{D_{h f}^{2}} \frac{D_{h r}^{2}}{D_{h f}^{2}}\right) \frac{\operatorname{Re}_{1}^{3}}{\left|\operatorname{Re}_{1}\right|} \\
& -H_{1} \frac{\rho^{2} D_{h r}^{2}}{\mu^{2}}=0 \\
& \vdots \\
& \left(P_{N}-P_{n}\right) \frac{\rho D_{h r}^{2}}{\mu^{2}} \frac{\operatorname{Re}_{n}}{\left|\operatorname{Re}_{n}\right|}+\left(\frac{D_{h r}^{2}}{D_{h c}^{2}}-\frac{D_{h c}^{2}}{D_{h f}^{2}} \frac{D_{h r}^{2}}{D_{h f}^{2}}\right) \frac{\operatorname{Re}_{n}^{3}}{\left|\operatorname{Re}_{n}\right|} \\
& \quad-H_{n} \frac{\rho^{2} D_{h r}^{2}}{\mu^{2}}=0 \\
& \left(P_{p}-P_{N+1}\right) \frac{\rho D_{h r}^{2}}{\mu^{2}} \frac{\operatorname{Re}_{p}}{\left|\operatorname{Re}_{p}\right|}-H_{p} \frac{\rho^{2} D_{h r}^{2}}{\mu^{2}}=0
\end{aligned}
$$

$$
\begin{aligned}
& \left(P_{N+1}-P_{A}\right) \frac{\rho D_{h r}^{2}}{\mu^{2}} \frac{\operatorname{Re}_{A}}{\left|\operatorname{Re}_{A}\right|}-H_{A} \frac{\rho^{2} D_{h r}^{2}}{\mu^{2}}=0 \\
& \vdots \\
& \left(P_{N}-P_{N+1}\right) \frac{\rho D_{h r}^{2}}{\mu^{2}} \frac{\operatorname{Re}_{N+1}}{\left|\operatorname{Re}_{N+1}\right|}-H_{N+1} \frac{\rho^{2} D_{h r}^{2}}{\mu^{2}}=0
\end{aligned}
$$

where $D_{h f}$ is the hydraulic diameter of the feed conduit part connected to the SFD land. The term $\mathrm{Re}_{i} /\left|R e_{i}\right|$ is introduced in the simplified form of the energy equation since the flow direction across each section of the feed system is not known beforehand. The pressure drop formulae are presented in the Appendix.

By denoting $W_{p}$, the net power supplied to the pump, the application of the energy equation to a control volume encompassing the oil reservoir up to the pump discharge, gives:

$$
\frac{W_{p}}{\rho Q_{p}}=\frac{P_{p}-P_{a m b}}{\rho}+\frac{V_{p}^{2}-V_{s}^{2}}{2}+H_{a}
$$

Knowing that the mean oil velocity at the reservoir surface, $V_{s}$, is considerably smaller than that at the pump discharge, $V_{p}$, and neglecting the pressure drop $H_{a}$, one can obtain the following non dimensional form of Equation (8):

$$
W_{p} \frac{\rho^{2} D_{h p}^{3}}{\mu^{3} A_{p}}=\left(P_{p}-P_{a m b}\right) \frac{\rho D_{h p}^{2} R e_{p}}{\mu^{2}}+\frac{R e_{p}^{3}}{2}
$$

Equations (4-7) and (9) make up the system of nonlinear equations from which the $4 n+4$ unknowns of the problem are calculated. To do so, the Newton-Raphson method is used and convergence is achieved after few iterations. This calculation is all the more efficient since the Jacobian matrix can be defined analytically. 


\section{RESULTS}

To illustrate the interaction between the feed system and the SFD, the unbalance response of a Jeffcott rotor (Vance, 1998) is analyzed. The following is defined for the problem:

- lumped mass at the rotor mid-point $\left(2 \mathrm{~m}_{1}\right): 90 \mathrm{~kg}$

- lumped mass at the bearing stations: $15 \mathrm{~kg}$

- shaft bending stiffness $\left(\mathrm{k}_{1}\right): 3 \times 10^{7} \mathrm{~N} / \mathrm{m}$

- retaining spring stiffness: $1 \times 10^{7} \mathrm{~N} / \mathrm{m}$

- viscous damping at the rotor mid-point: $300 \mathrm{~N} \cdot \mathrm{s} / \mathrm{m}$

- SFD length: $40 \mathrm{~mm}$

- SFD radius: $75 \mathrm{~mm}$

- SFD radial clearance $(C): 0.3 \mathrm{~mm}$

- fluid viscosity: $0.008 \mathrm{~Pa} \cdot \mathrm{s}$

- fluid density: $930 \mathrm{~kg} / \mathrm{m}^{3}$

- $C l=5 \times 10^{-11} \mathrm{~m}^{2} / \mathrm{Pa} \cdot \mathrm{s}$ (tight piston ring seals)

- $\varsigma=1.8 \times 10^{-4} \mathrm{~m}$

Static forces are neglected so that the damper operates centered within the clearance space. The Jeffcott unbalance response is calculated by the Trigonometric Collocation Method (TCM) (Nataraj and Nelson, 1989) conjugate with the Pseudo-arc Length Continuation Method (Nayfeh, 1995), in the rotor speed range defined by $0<\omega_{a d}<5$, where $\omega_{a d}=$ $\omega /\left(\mathrm{k}_{1} / \mathrm{m}_{1}\right)^{1 / 2}$. Stability is inferred from Floquet theory (Nayfeh, 1995) and the monodromy matrix is determined following the method developed by Hsu (1972). In what follows, the influence of the number of feed holes and the power supplied to the pump on the dynamics of the rotor as well as on the hydraulic system behavior is analyzed.

\section{Influence of the Number of Feed Holes on the Dynamics of the Jeffcott Rotor}

Figure 3 shows the amplitude of the first harmonic in the SFD response, adimensionalized with respect to $C$, versus the dimensionless rotor speed, for different numbers of feed holes. We can notice first that all damper configurations generate enough damping, due mainly to their tightly sealed extremities, to lock out the retaining springs. As a consequence, the Jeffcott's first critical speed is suppressed and the SFD vibration amplitudes at the second critical speed are only lightly affected by the number of feed holes. Away from the resonance, the damper vibration amplitudes are seen to be magnified when the number of oil injection holes is augmented. This result follows from the reduction of the hydrodynamic forces magnitude caused by the diminution of the effective squeezing surface.

Figure 4 depicts the higher non negligible harmonics in the SFD response, adimensionalized with respect to $C$. Even though they are seen to be quite small in comparison to the first harmonic, they have to be taken into account in the calculations or else the TCM may fail to converge. Comparison between

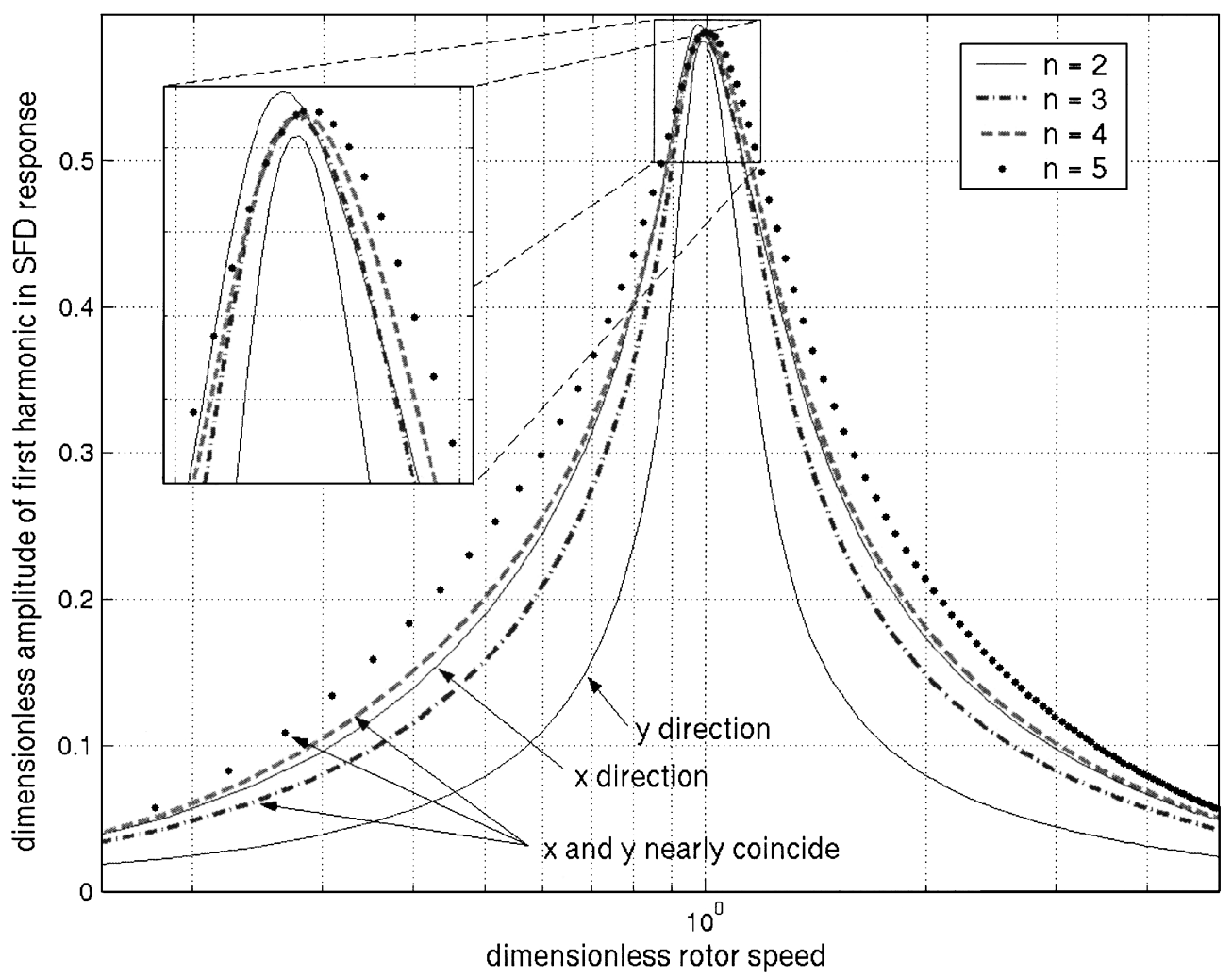

FIGURE 3

SFD unbalance response. First harmonic amplitude: $W_{p}=100 \mathrm{~W}$. 


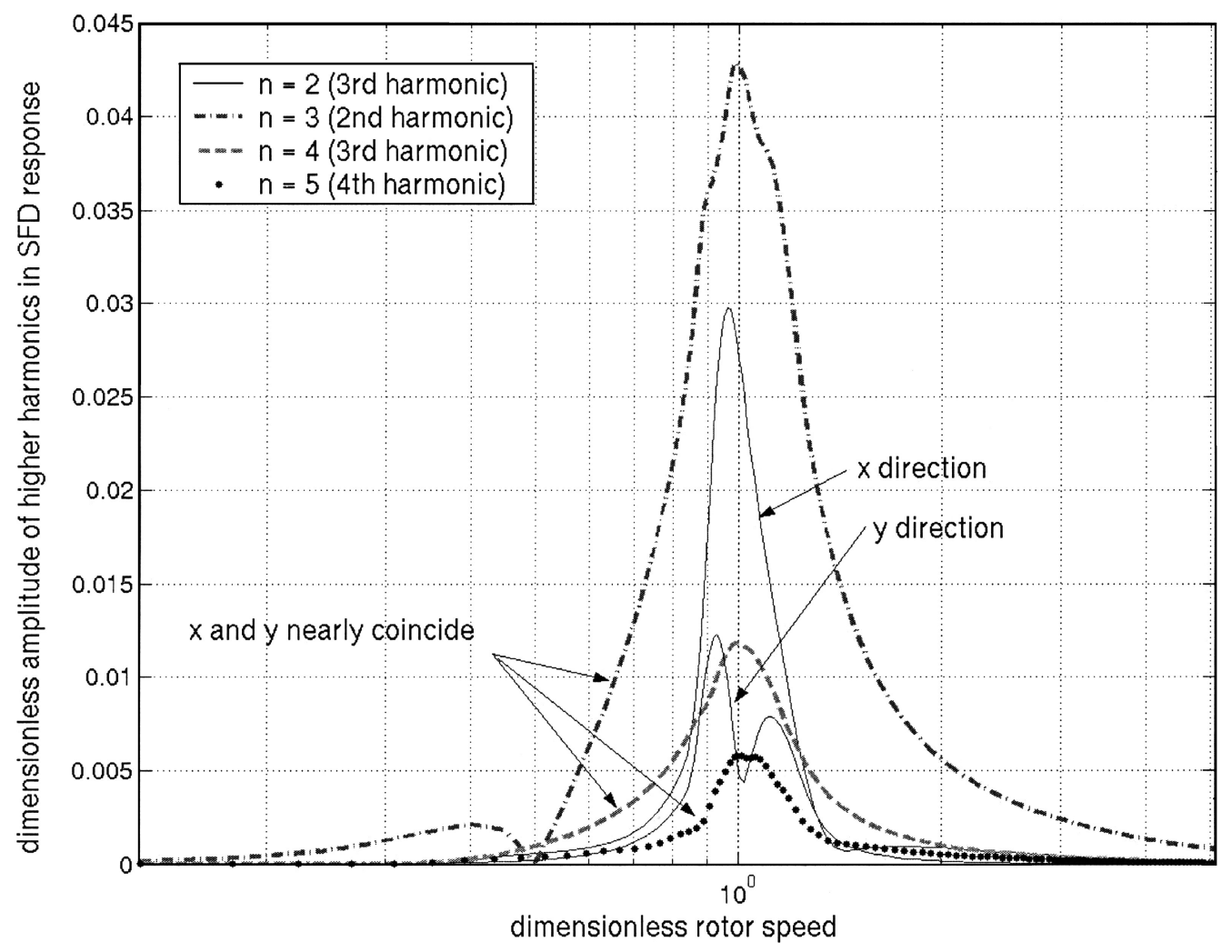

FIGURE 4

SFD unbalance response. Higher harmonics amplitude: $W_{p}=100 \mathrm{~W}$.

Figures 3 and 4 indicate that the unbalance responses are nearly purely harmonic. Note also that while the orbits of the two holes fed SFD are nearly elliptical, as the number of feed holes is increased, the damper orbits become almost circular. This result agrees with that obtained by Wang and Hahn (1995). For an even number of feed holes, the odd higher harmonics appear to be the most relevant in the damper response, whereas the even harmonics show up when the SFD is fed by an odd number of holes.

The influence of the number of feed holes on the rotor stability can be inferred from Figure 5, which illustrates the evolution of the leading Floquet multiplier as a function of the dimensionless rotor speed. No unstable behavior is observed within the speed range considered. The leading Floquet multiplier furnishes information about the time the system takes to return to its stable original orbit after a perturbation is applied. Hence, we can remark from Figure 5 that, for this specific example, the increase in the number of feed holes improves the rotor stability, especially away from the critical speed. This observation can be confirmed by estimating the damper dissipation, $\dot{w}$, through the expression $\dot{w}=F_{t} e \omega$, where $F_{t}$ is the tangential hydrodynamic force and $e$ the journal eccentricity. The tangential hydrodynamic force diminishes as the number of feed holes increases, as does the radial force, so that the damper journal eccentricity becomes larger. The conjunction of these factors results in that the five holes fed SFD dissipate indeed more energy than the other configurations.

Regarding the SFD transmissibility, better housing vibration isolation is obtained by increasing the number of feed holes, as shown in Figure 6. The transmissibility varies over a rotation period at a given rotor speed, as the hydrodynamic forces fluctuate because of the presence of the feed holes, as exemplified in Figure 7. We can perceive that the radial force contributes considerably to the transmissibility of the two feed holes configuration. As the number of feed holes increases, the radial force as well as its peak-to-peak value diminishes, nearly vanishing for the five holes fed SFD, which reflects an almost purely dissipative damper behavior. Since the orbits are centered and nearly circular, a low radial force magnitude also indicates that cavitation is better prevented by feeding the SFD through a higher number of injection holes. The feed system hydrostatic effects are evidenced by the transmissibility evolution at low rotor speed (see Figure 6) as well as the positive radial forces observed in Figure 7.

\section{Influence of the Power Supplied to the Pump on the Dynamics of the Jeffcott Rotor}

The influence of the power supplied to the pump on the rotor response is analyzed for $W_{p}=50,100,200$, and 400 watts. Figure 8 depicts the results obtained for the four holes fed SFD. 


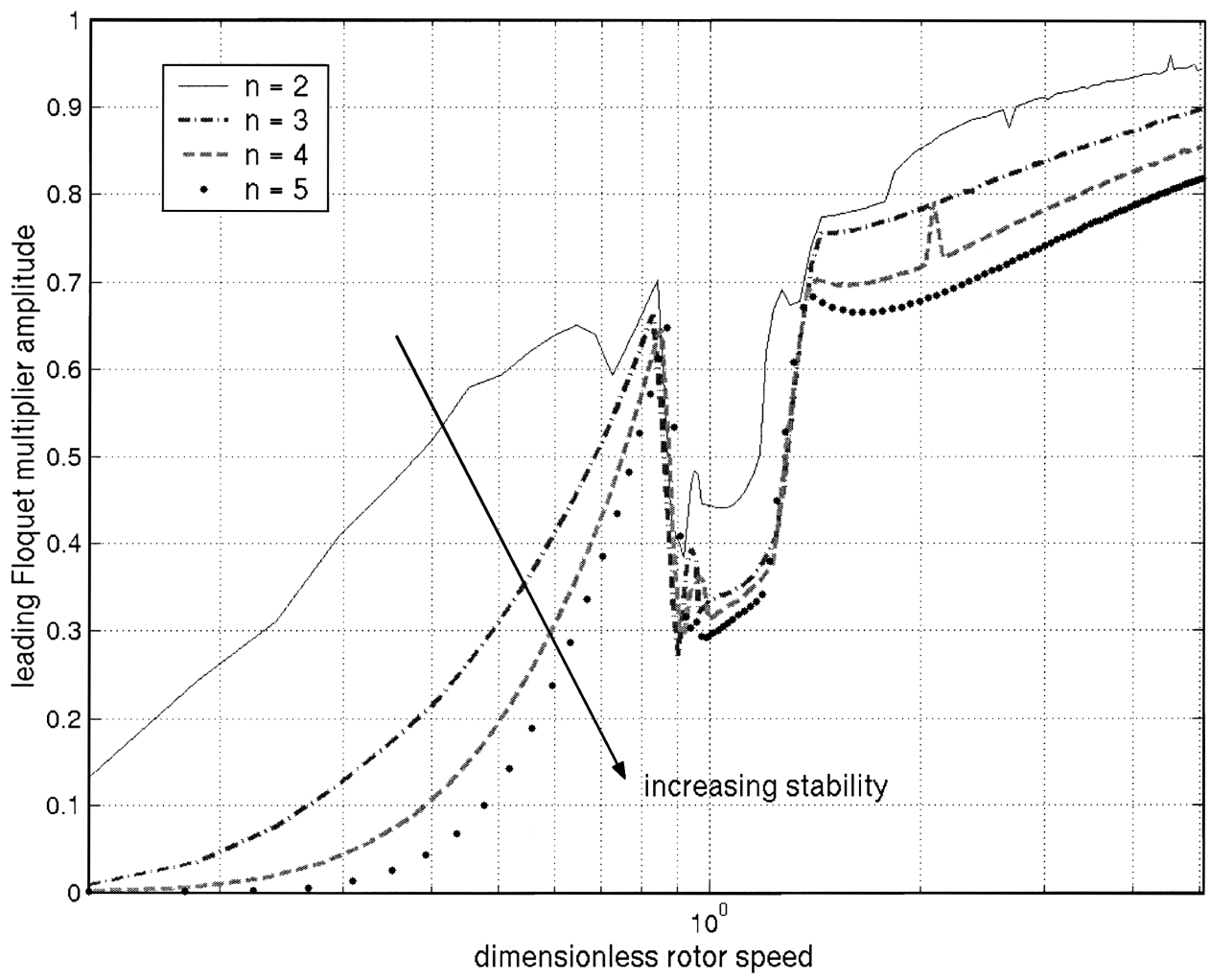

FIGURE 5

Rotor stability analysis: $W_{p}=100 \mathrm{~W}$.

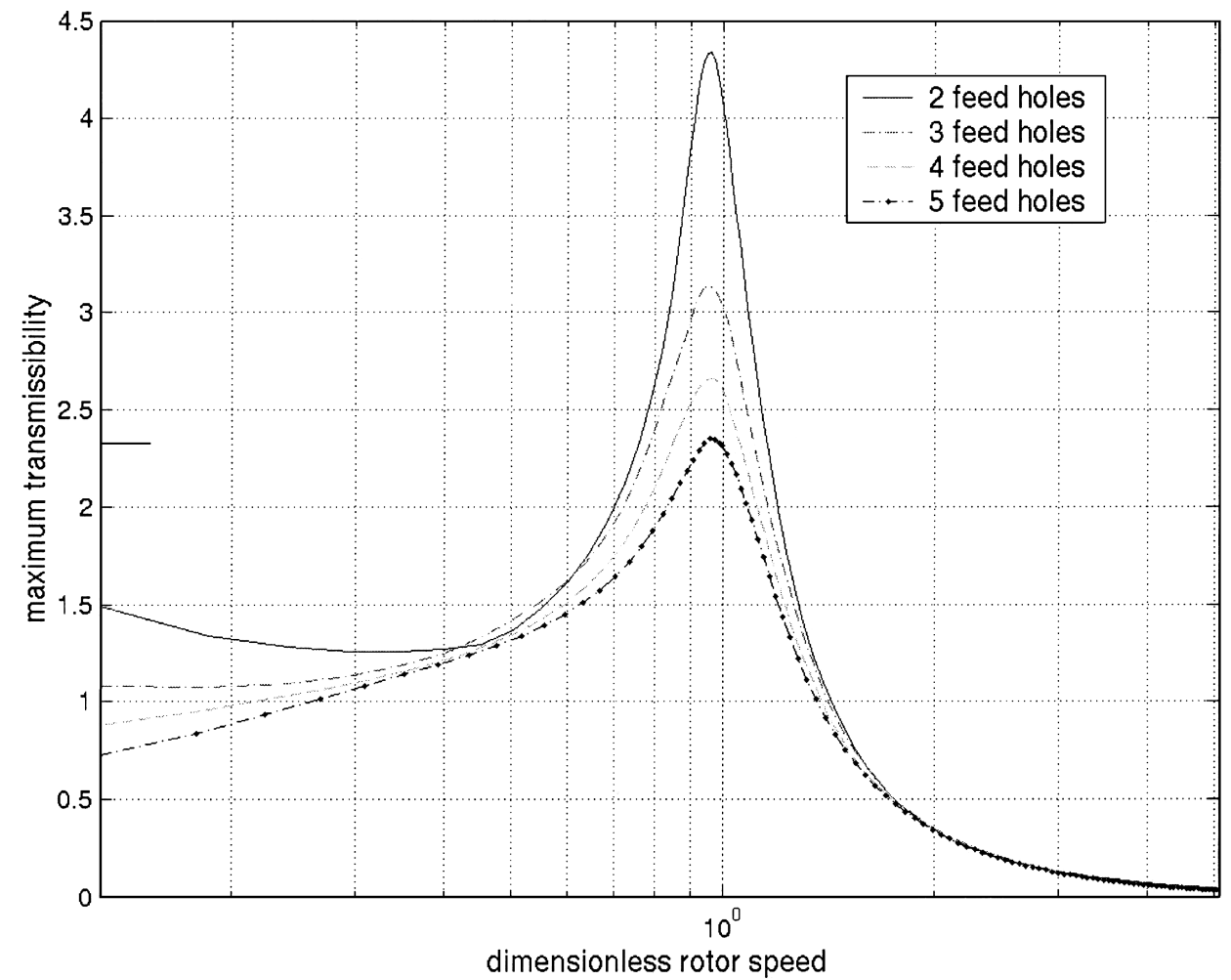

FIGURE 6

SFD maximum transmissibility: $W_{p}=100 \mathrm{~W}$. 

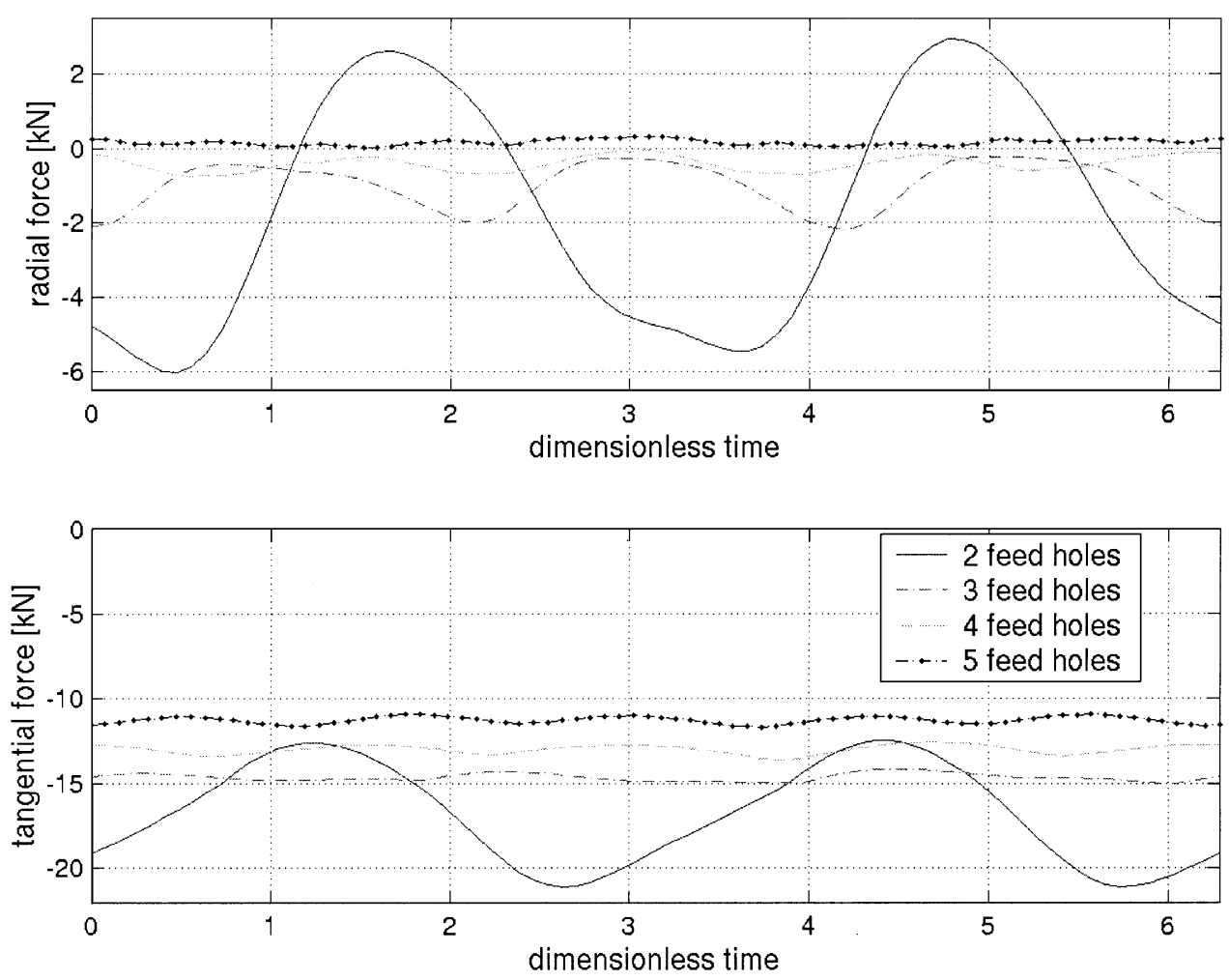

FIGURE 7

Hydrodynamic forces evolution over a period at $\omega_{a d}=0.96: W_{p}=100 \mathrm{~W}$.

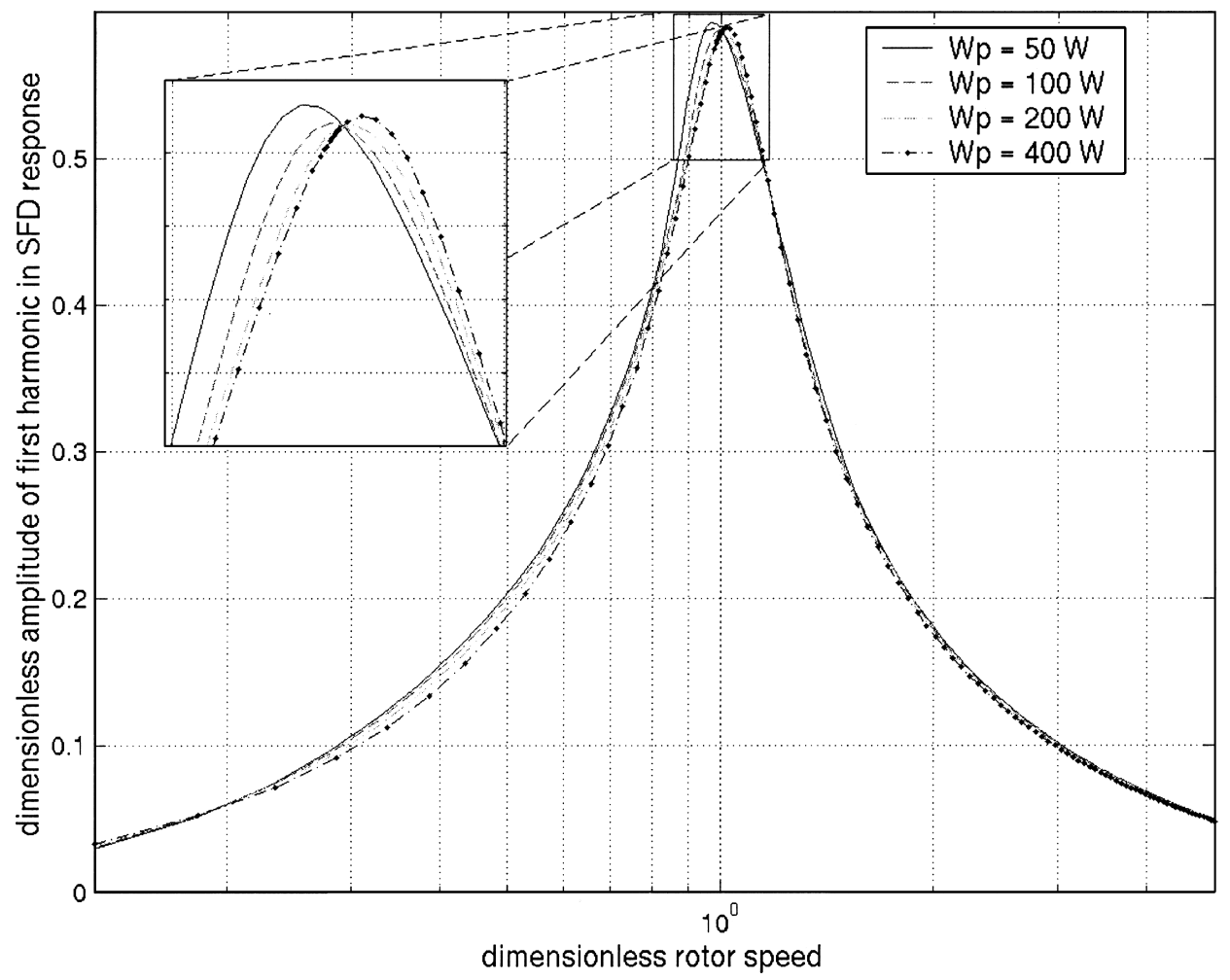

FIGURE 8

SFD unbalance response. First harmonic amplitude: $n=4$. 


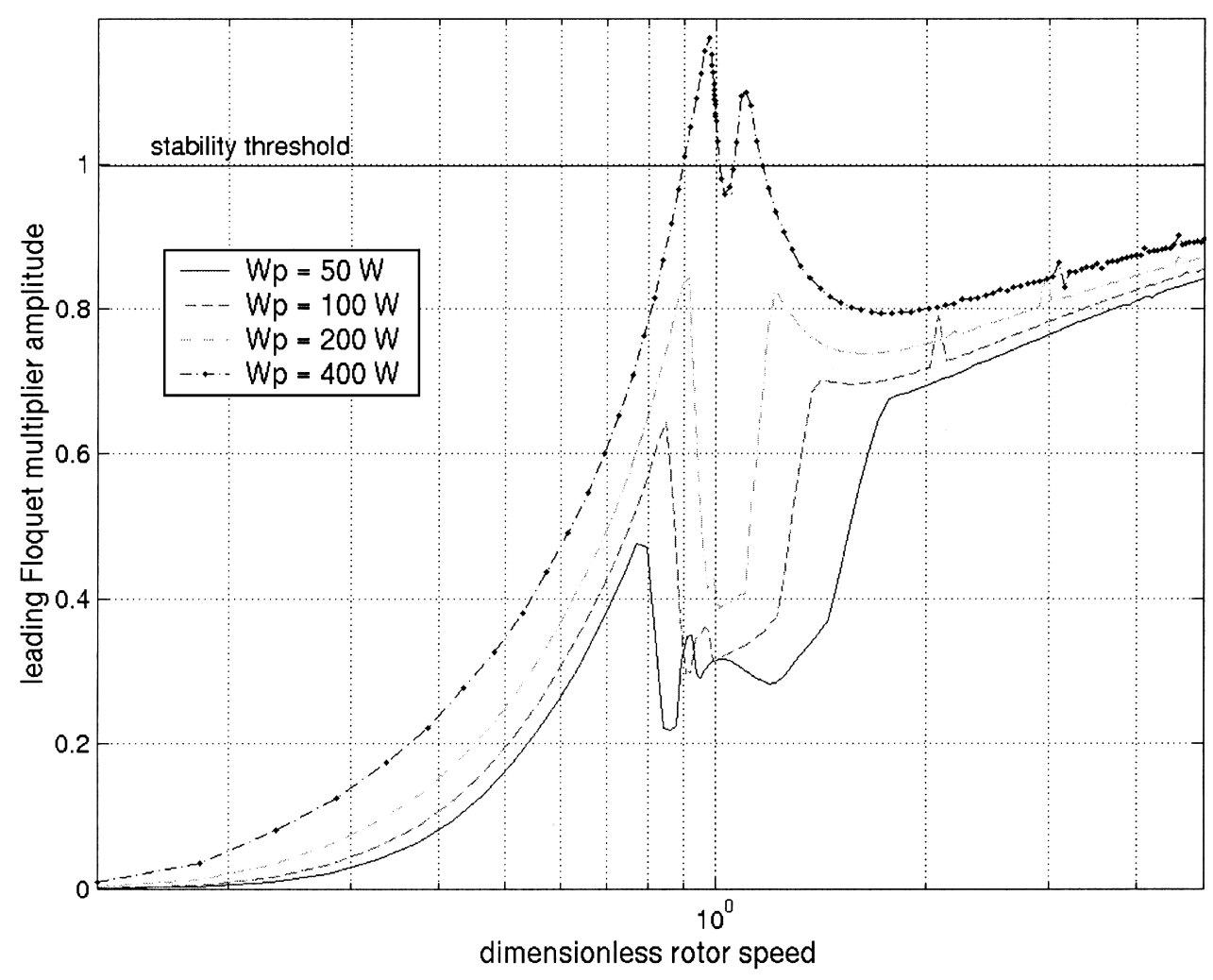

FIGURE 9

Rotor stability analysis: $n=4$.

We can notice that an increase in the power supplied to the pump makes the critical speed move forward and attenuates the SFD vibration amplitude over almost all the speed range. The same is observed concerning the higher harmonics, but the curves are not presented here for the sake of saving space. The SFD unbalance responses differ slightly before the resonance peak and after it they are virtually the same. Similar trends are observed for all feed system configurations.

The sensitivity of the rotor behavior to the power supplied to the pump is more pronounced in terms of the rotor stability, as illustrated in Figure 9. In the light of the preceding discussion about the signification of the leading Floquet multiplier, the rotor stability is seen to deteriorate as more power is supplied to the pump. This deterioration arises as a consequence of the increase in the hydrostatic effects, which produce negative cross-coupled damping (i.e., positive radial forces), thus destabilizing the rotor whenever they grow too prominent. However, it is important to remark that, at the threshold of stability, the pressures and flows in the feed system may reach very significant values as a result of the pump power augmentation. Hence, the hypothesis of laminar flow made in the development of the feed system model might no longer be valid. In hydraulics, the laminar-toturbulent transition is commonly assumed to occur at $\mathrm{Re}=2300$ (Idel'Cik, 1969).

The vibration isolation properties of the SFD are also improved by the reduction of the power supplied to the pump, as shown in Figure 10. This is verified especially at low speeds, at which the hydrostatic contribution to the damper forces is more important. At higher speeds, the hydrodynamic effects are preponderant so that the transmissibilities calculated are nearly identical.

\section{Hydraulic System Behavior}

The model developed in this work allows for a close look at the feed system behavior. The pump operation is of course modeled in quite a simplified way, since its efficiency is supposed to be constant, while in practice it depends on the flow rate. The energy approach employed here may nevertheless provide pertinent information about the interaction between the SFD and its feed system. For instance, we can conclude from Figure 11 that the imposition of a constant pressure as a boundary condition in the modeling of a SFD is not realistic. The mean pump exit pressure is seen to be a function of the kinematics of the damper journal. When passing through the critical speed, the SFD pump-like effect is seen to cause an important pressure increase at the pump exit. Even though this fact may not noticeably modify the rotor unbalance response, the calculation of the oil flow into the film may be completely incorrect.

In addition to the pump exit pressure variation as a function of the rotor speed, important fluctuations are also observed 


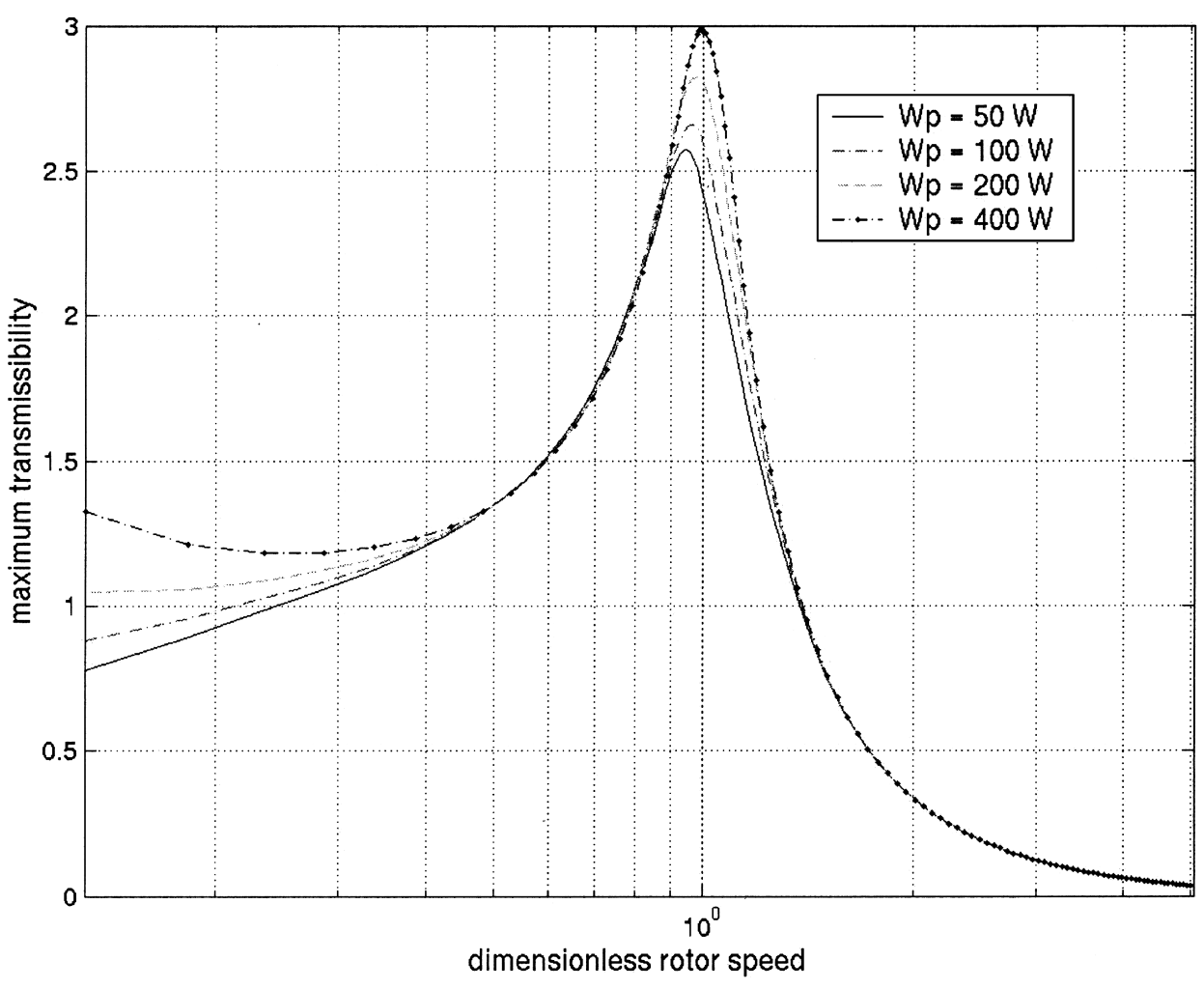

FIGURE 10

SFD maximum transmissibility: $n=4$.

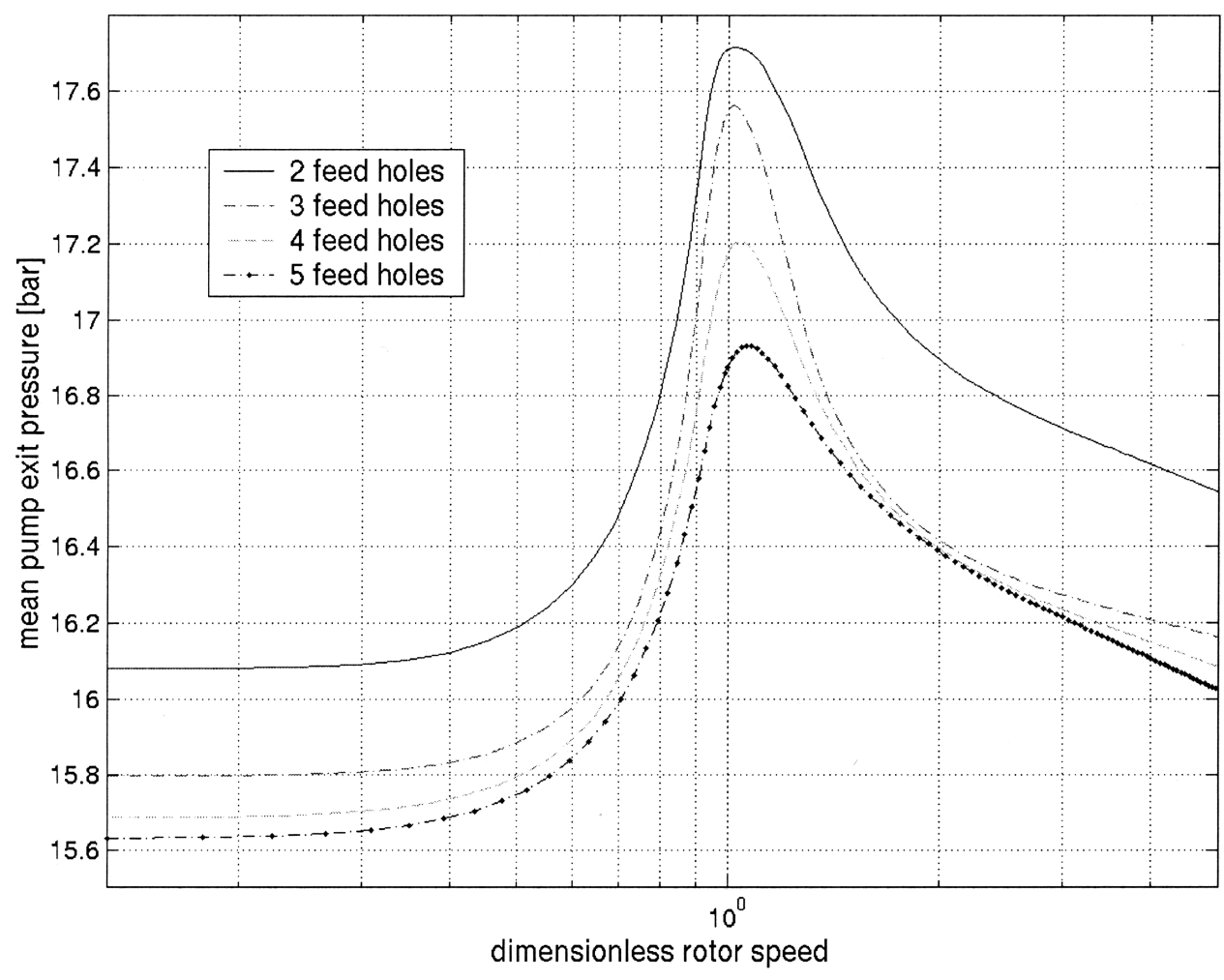

FIGURE 11

Feed system response. Mean pump exit pressure: $W_{p}=100 \mathrm{~W}$. 


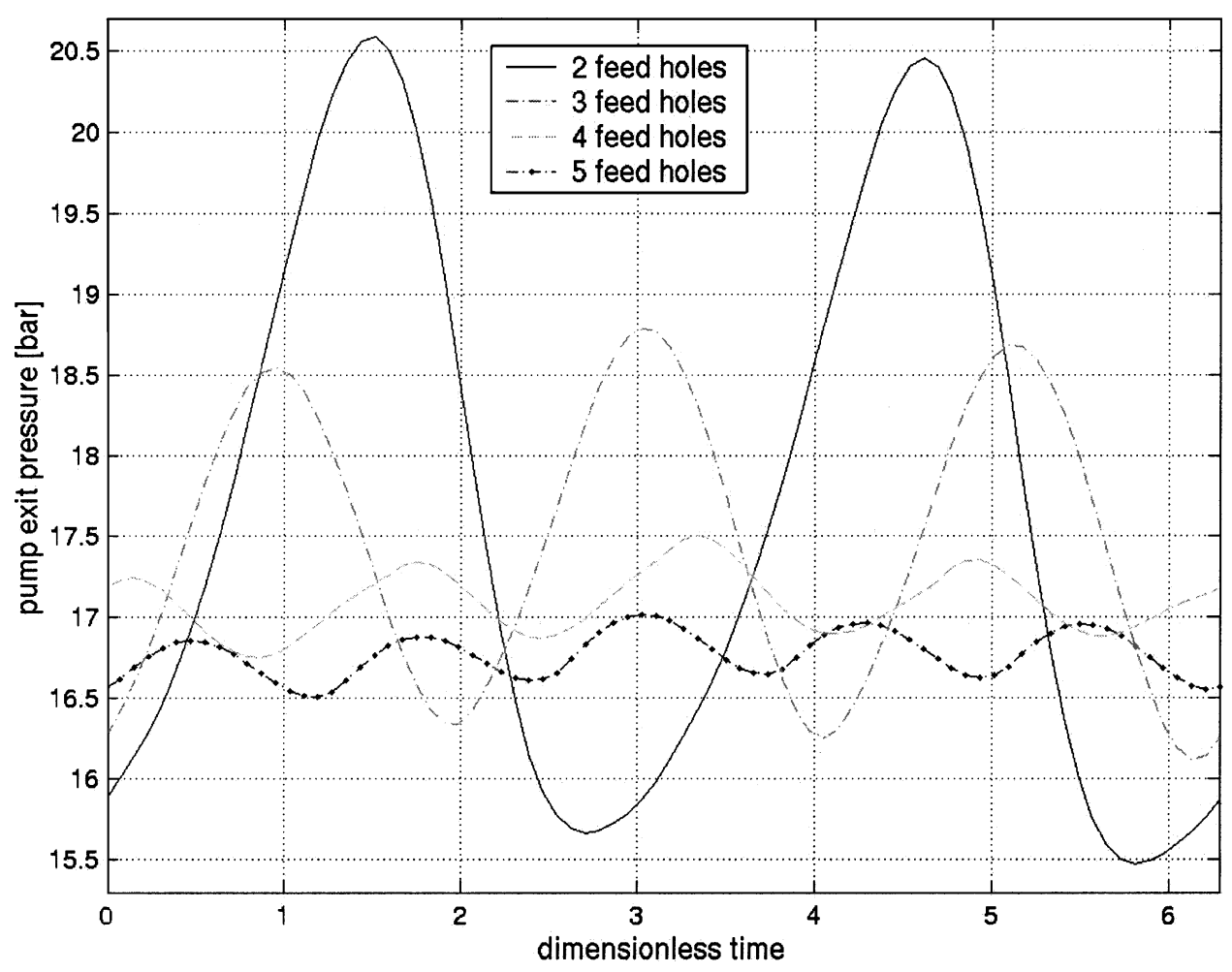

FIGURE 12

Pump exit pressure fluctuation over a period at $\omega_{a d}=0.96: W_{p}=100 \mathrm{~W}$.

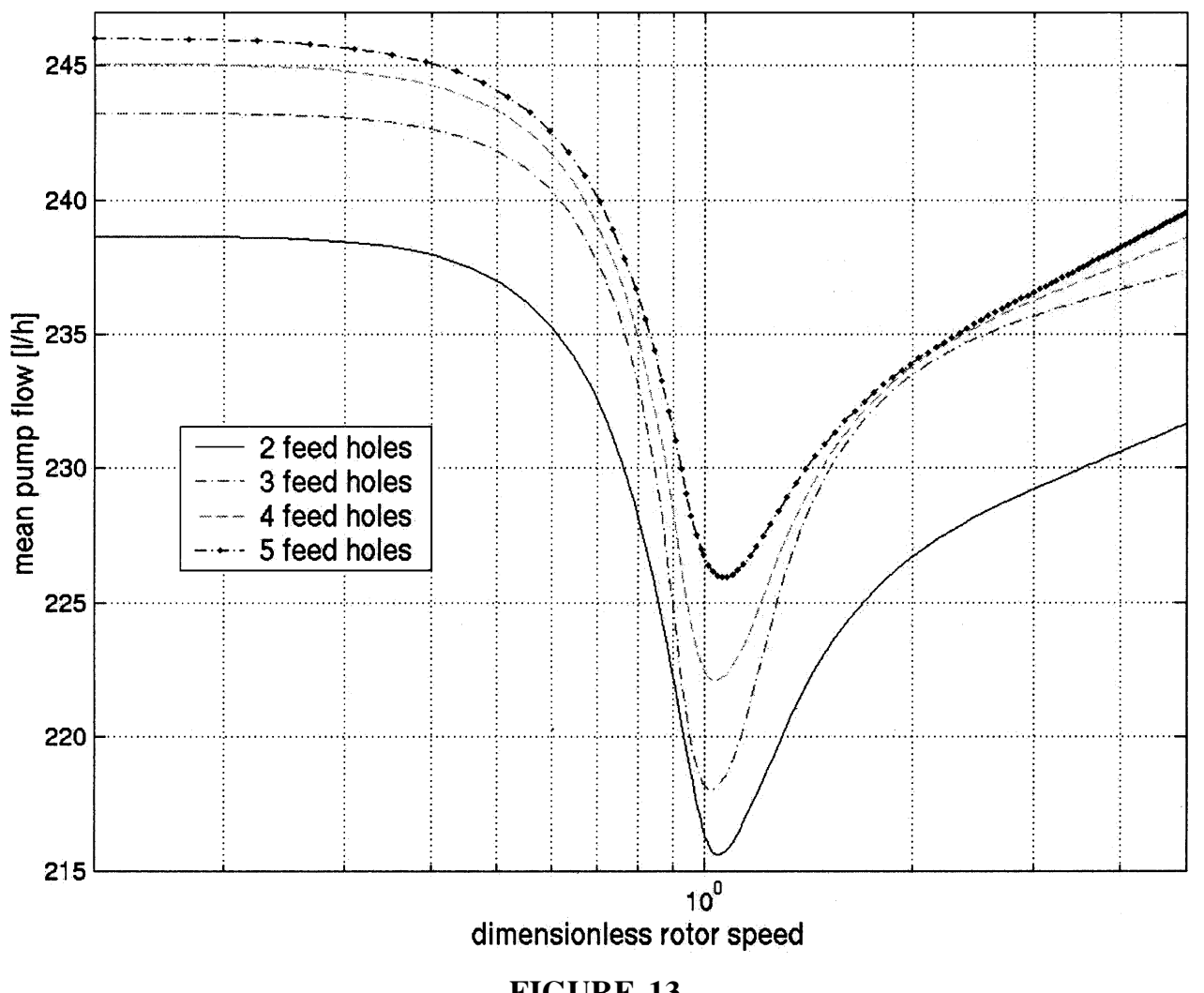

FIGURE 13

Feed system response. Mean pump flow: $W_{p}=100 \mathrm{~W}$. 
over a rotation period at a given speed, as exemplified in Figure 12. The peak-to-peak pump exit pressure fluctuations are especially large for the two-hole fed SFD and they decrease as the number of injection holes is augmented. For the five holes configuration, the pump exit pressure may be regarded as constant over a rotation period, however it still undergoes non negligible shifts as the shaft speed changes. The pressure fluctuations are seen to be even larger at the injection holes. Two conjugate factors can be pointed out to explain this observation: (1) the occurrence of cavitation and (2) the change in the feed conduits cross-sectional area (see Figure 2). When the oil flows into the film, the reduction of the conduit cross-sectional area causes part of the static pressure energy to be converted into kinetic energy as the flow velocity increases in order that mass conservation is verified. When the cavitation zone passes in front of the feed hole, the flow, and consequently the pressure loss, are maximum so that the pressure attains its smallest value, far below the pump exit pressure. On the other hand, when the oil is pumped back to the feed system, the energy is converted in the opposite direction and the pressure level is seen to remain close to that observed at the pump exit.

The SFD pump-like action is also remarkable in Figure 13, which depicts the mean pump flow versus the dimensionless rotor speed. The feed capability of the hole injection system is seen to decrease when the damper's eccentricity and precession velocity increase. Furthermore, the number of feed holes is seen to affect the amount of oil injected into the film only slightly. The feed capability is, on the other hand, very sensitive to the net power supplied to the pump, a logical result in view of the energy approach employed.

\section{CONCLUSIONS}

In the present work, a model coupling the SFD behavior with the hydraulic feed system performance has been developed. The damper pressure distribution is considered to be governed by the Reynolds equation and the presence of end seals is taken into account by the introduction of an end leakage coefficient. The use of the simplified form of the energy equation commonly used in hydraulics allows for the description of pressure and flows in the hole feed system. The interaction between the hydrodynamic and hydraulics problems is modeled via flow balancing at the injection holes.

It is difficult to draw general conclusions about the influence of the feed system on the dynamics of a flexible rotor, since it depends on the rotor configuration itself. The augmentation of the pump power and the reduction of the number of feed holes lead to an increase in the SFD damping, thus rendering it dynamically stiffer. If this dynamic stiffness is excessive, as in the case of the Jeffcott rotor considered in this work, the results of the numerical simulations carried out demonstrate that an increase in the number of feed holes and a reduction in the pump power may ameliorate the damper performance since it maximizes the energy dissipation. Rotor stability is hence improved and transmissibility is reduced.

Important hydrostatic effects introduced by the feed system are observed, especially at low speeds. If the damper motion is circular and centered, these effects may be regarded as negative cross-coupled damping. Consequently, they are seen to be potentially destabilizing when magnified by means of supplying more power to the pump. On the other hand, the use of a more powerful pump conjugate with a feeding through more holes better prevents oil cavitation.

The pressures in the feed system vary considerably in function of the damper kinematics. They are far from being constant, as commonly supposed in the definition of the SFD's boundary conditions, what may lead to important errors in the estimation of the feed capacity of the hydraulic system.

\section{NOMENCLATURE}

$\mathrm{Cl} \quad$ end leakage coefficient $\left[\mathrm{m}^{2} / \mathrm{Pa} \cdot \mathrm{s}\right]$

$\left\{F_{\text {land }}\right\} \quad$ land squeeze flow vector $[\mathrm{m} / \mathrm{s}]$

$h \quad$ film thickness [m]

$H_{i} \quad$ pressure drop related to flow $Q_{i}[\mathrm{~J} / \mathrm{kg}]$

$[K] \quad$ fluidity matrix $[\mathrm{m} / \mathrm{Pa} \cdot \mathrm{s}]$

$n \quad$ number of feed holes

$P_{0} \quad$ ambient pressure [Pa]

$\left\{P_{\text {land }}\right\} \quad$ vector of pressures in the SFD land [Pa]

$\left\{P_{\text {hole }}\right\} \quad$ vector of pressures at the feed holes $[\mathrm{Pa}]$

$P_{i} \quad$ pressures in the hydraulic system [Pa]

$q_{z} \quad$ lineal local flow rate $\left[\mathrm{m}^{3} / \mathrm{s} / \mathrm{m}\right]$

$Q_{i} \quad$ flows in the hydraulic system $\left[\mathrm{m}^{3} / \mathrm{s}\right]$

$\left\{Q_{\text {hole }}\right\}$ vector of flows across the feed conduits $\left[\mathrm{m}^{3} / \mathrm{s}\right]$

$R \quad$ SFD radius [m]

Re Reynolds number

$z \quad$ axial coordinate

$W_{p} \quad$ net power supplied to the pump [W]

$\rho \quad$ fluid density $\left[\mathrm{kg} / \mathrm{m}^{3}\right]$

$5 \quad$ mass eccentricity of the rotor [m]

$\mu \quad$ fluid dynamic viscosity [Pa.s]

\section{REFERENCES}

Arauz, G. L., and San Andres, L. A. 1994. Effect of a circumferential feeding groove on the dynamic force response of a short squeeze film damper. ASME Journal of Tribology 116:369-377.

Chen, P. Y. P., and Hahn, E. J. 1994. Pressure distribution in squeeze film dampers with oil hole feed, IMechE, Part J. Journal of Engineering Tribology 208:105-112.

Diaz, S., and San Andres, L. A. 2001. A model for squeeze film dampers operating with air entrainment and validation with experiments. ASME Journal of Tribology 123:125-133.

Gohar, R. 1988. Elastohydrodynamics. Ellis Horwood Series in Mechanical Engineering.

Hsu, C. S. 1972. Impulsive parametric excitation: Theory. Journal of Applied Mechanics, pp. 551-558. 
Idel'Cik, I. E. 1969. Memento des pertes de charge. Paris, Eyrolles Editeur.

Lund, J. W., Smalley, A. J., Tecza, J. A., and Walton, J. F. 1983. Squeezefilm damper technology: Part 1-prediction of finite length damper performance. ASME paper 83-GT-247.

Marmol, R. A., and Vance, J. M. 1978. Squeeze film damper characteristics for gas turbine engines. ASME Journal of Mechanical Design 100:139-146.

Nataraj, C., and Nelson, H. D. 1989. Periodic solutions in rotor dynamic systems with nonlinear supports: A general approach. Journal of Vibration, Acoustics, Stress, and Reliability in Design 111:187193.

Nayfeh, A. H., and Balachandran, B. 1995. Applied Nonlinear Dynamics. John Wiley \& Sons, New York.

San Andres, L. A. 1992. Analysis of short squeeze film dampers with a central groove. ASME Journal of Tribology 114:659-665.

Vance, J. M. 1998. Rotordynamics of Turbomachinery. John Wiley \& Sons, New York.

Wang, J., and Hahn, E. J. 1995. Transient analysis of squeezefilm dampers with oil hole feed. Tribology Transactions 38:837844.

\section{APPENDIX}

The pressure drops in hydraulic systems are composed by distributed and singular energy losses caused by friction and obstacles, respectively. In the case of a laminar flow, the friction pressure drop in a $L$ meters long conduit with a $D_{h}$ hydraulic diameter is given by (Idel'Cik, 1969):

$$
H_{f r}=32|\operatorname{Re}| \frac{L}{D_{h}^{3}} \frac{\mu^{2}}{\rho^{2}}
$$

Singular pressure drops can be expressed in the following general form (Idel'Cik, 1969):

$$
H_{s g}=\xi \frac{\mu^{2}}{\rho^{2} D_{h}^{2}} \frac{\mathrm{Re}^{2}}{2}
$$

where $\xi$ is the singular pressure drop coefficient.

For the feed system configuration considered in the present work, three main types of singular energy loss are identified. They are due to flow separation/reunion at the system intersections, flow expansion/contraction and direction changes at the feed conduits, and flow discharge into the film. The pressure drop coefficients for these types of energy loss are estimated from the abacuses 3.13, 7.7, 7.25, 7.29, 11.6, and 11.13 of reference (Idel'Cik, 1969). In view of typical orders of magnitude of feed flows and feed conduits dimensions, the pressure drop caused by flow separation/reunion is seen to be very small in comparison with the other types of energy loss and is hence neglected. 

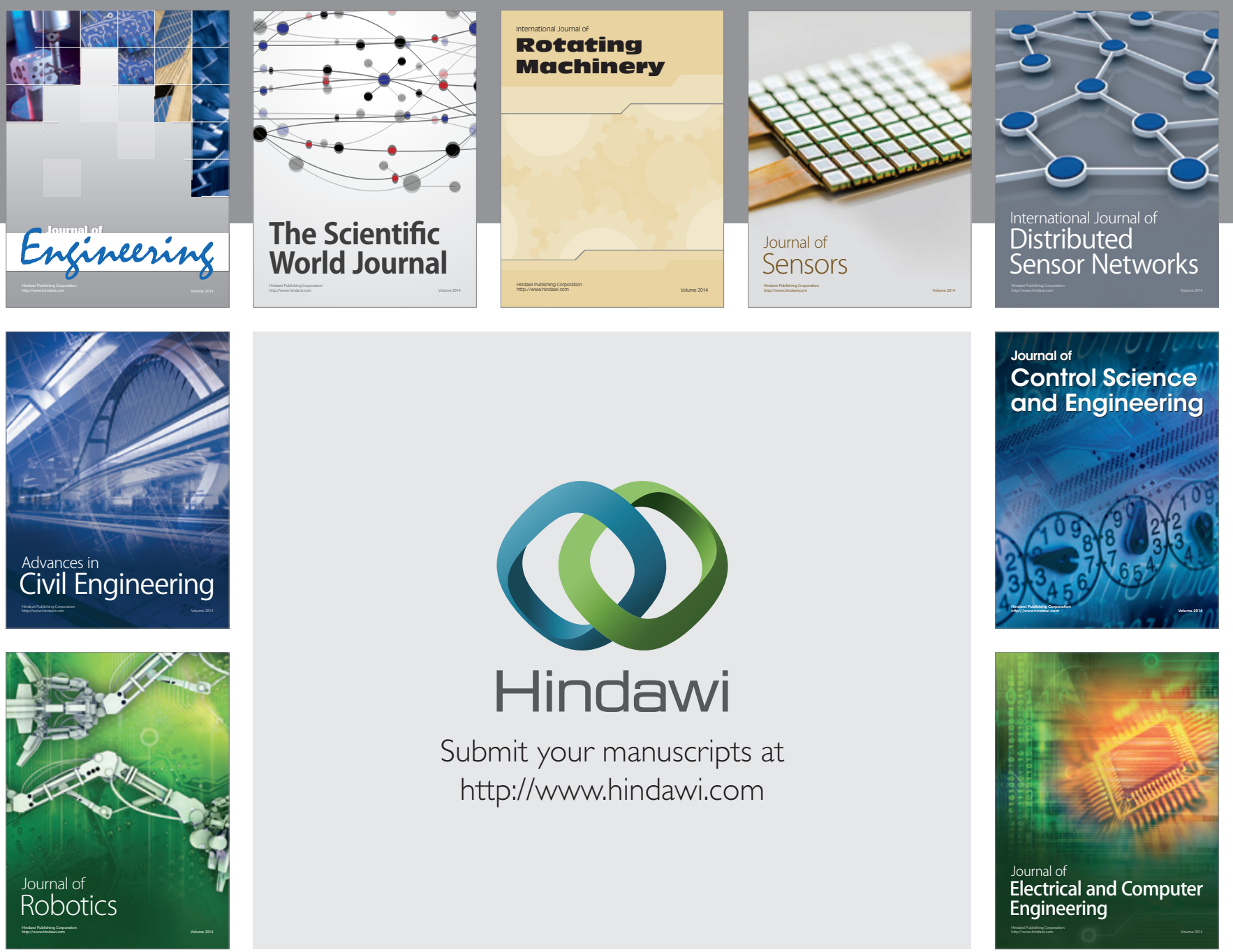

Submit your manuscripts at

http://www.hindawi.com
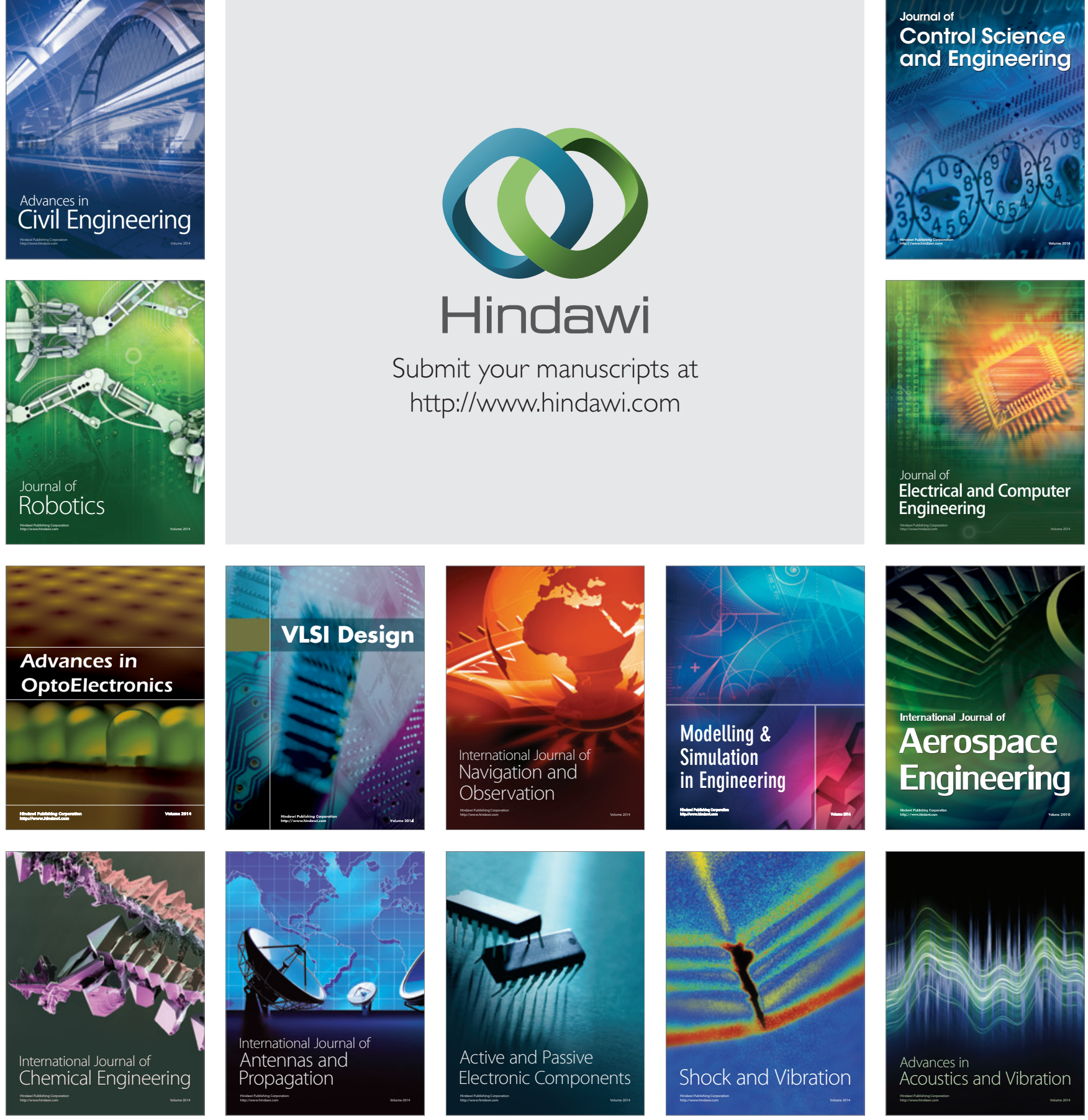